\title{
Publishing performance in economics: Spanish rankings (1990-1999)
}

\author{
Juan J. Dolado ${ }^{1}$, Antonio García-Romero ${ }^{1,2}$, Gema Zamarro ${ }^{3}$ \\ 1 Department of Economics. Universidad Carlos III de Madrid, c/ Madrid, 126, 28903 Getafe (Madrid), \\ Spain (dolado@eco.uc3m.es)) \\ 2 Universitat Oberta de Catalunya, 08035 Barcelona, Spain (e-mail; help@eco.vc3m.es) \\ 3 CEMFI, 28014 Madrid, Spain (e-mail: gzamarro@cemfi.es)
}

\begin{abstract}
This paper contributes to the growing literature that analyses the Spanish publishing performance in Economics throughout the 1990s. Several bibliometric indicators are used in order to provide Spanish rankings (of both institutions and individual authors) based on Econlit journals. Further, lists of the ten most influential authors and articles over that period, in terms of citations, are reported.
\end{abstract}

JEL Classification: A110, A140

Key words: Rankings, economics, bibliometric indicators

\section{Introduction}

The recent history of scientific research in Spain dates back to the implementation of the Ley de la Ciencia in 1986 which provided a legal framework for the creation of specific policies (R\&D National Plans) promoting R\&D activities in all scientific disciplines. As a consequence of this new environment, measurement of Spanish scientific productivity becomes a key tool in assessing the efficacy of research policies. For example, decision makers should make use of this information in order to allocate research funds among high- performance groups or to design appropriate reward and promotion stuctures within research units (universities and research centers). In this respect, some studies on the evaluation of specific policies, disciplines and institutions have been undertaken, with the common finding of a significant increase in the scientific output (measured in terms of publishing performance and other dimensions) produced in Spain during the 1990s. In particular,

We are grateful to many colleagues who made very useful remarks to preliminary versions of this paper, as well as to two anonymous referees. We are particularly indebted to Xavier Sala-i-Martín, without whose invaluable help this work would not have been possible. All errors or omissions are of our exclusive responsibility. 
the Spanish share of total world scientific production has increased from $1.55 \%$ to $2.75 \%$ throughout that decade (see OCYT 1999). In line with this overall improvement, Spanish research in Economics has evolved positively, both in quantitative (number of publications) as in qualitative (influence of publications) terms (see, e.g., Urrutia 1993). This favourable trend has also been identified in internationalscope studies measuring the quality of scholarly productivity in Economics (see, e.g., the four evaluation studies recently commissioned by the European Economic Association ${ }^{1}$ ) where some Spanish research units appear in very prominent positions.

However, it is only recently that a small number of careful studies centered around the specific aspects of Spanish research in Economics have appeared. ${ }^{2}$ This article adds to this still scarce but growing literature by addressing the following two questions: (i) Which are the most productive Spanish institutions in terms of publications during the 1990s?, and (ii) Who are the most productive and influential researchers in Spain over that period? Providing answers to these questions can be useful for a few potential users of this type of studies such as: (i) Evaluation Agencies and Funding Bodies in their grant-allocation decisions; (ii) Undergraduates seeking for good universities where to complete a degree in Economics; and (iii) Young $\mathrm{Ph}$.Ds interested in pursuing further research at the best institutions. ${ }^{3}$

The bibliometric indicators used in this study are based on the number articles published by each researcher or institution, weighted by number of authors in each publication and by the journal's quality, according to the information gathered from the Econlit database. Additionally, we consider some further indicators based on citation analysis, such as the ranking of the ten authors who have received more citations, or the ten most-cited papers written by Spanish economists during the 1990s. The citation data have been drawn from "The Web of Science" of the Institute for Scientific Information (ISI).

Once the main goals have been outlined, it is interesting to highlight which are the main methodological differences between our paper and other similar studies on Spanish scholarly research in Economics. A key difference is that the available studies have only focused on institutional rankings, yet no attempt has been made to construct individual ones, as we do here. Further, the period examined in this article (1990-1999) is longer than those considered in previous studies. For instance, García et al. (1999a) provide a ranking of Spanish institutions based upon one of the weighting schemes used in this paper ( $B R$, see Sect. 2), yet considering a shorter period (1992-1997) than ours. Likewise, García et al. (1999b) restrict their analysis to the publications available in Spanish journals during that period. Sanz et al. (1999) examine the evolution of the scientific production in Economics during the first half of 1990s. Finally, Bergantiños et al. (2002) focus on publications throughout the second half of the 1990s (1995-1999) and use indicators based on the Journals' Impact Factors from Institute for Scientific Information. In general, these

\footnotetext{
1 These studies are available at www.eeassoc.org.

2 Most of those studies can be found at www.fedea.es.

3 There is a long tradition of ranking Economics Departments in the US, with the above goals in mind, which dates back to Fusfeld (1956). See, inter alia, Graves et al. (1982), Conroy and Dusansky (1995), Medoff (1996), Scott and Mitias (1996), Dusansky and Vernon (1998), and Thusrsby (2000).
} 
studies identify a small group of leading research units. Typically, these are four public universities: Alicante, Autónoma de Barcelona (UAB), Carlos III (UCIII) and Pompeu Fabra (UPF), and two research centers: IAE (Instituto de Análisis Económico/CSIC) and CEMFI (Centro de Estudios Monetarios y Financieros).

The rest of the paper is organized as follows. Section 2 is devoted to describe the publications database, as well as to justify the set of weighting schemes and indicators used to measure scientific output. Section 3 presents the rankings by institutions and individual authors. Section 4 presents citation-based rankings including the list of ten most-cited papers in the 1990s. Finally, Sect. 4 draws some conclusions.

\section{Data and methodology}

\subsection{Data}

There are several data sources that can be used to elaborate this type of rankings, being Econlit and the Social Science Citation Index (SSCI) the two most frequently databases used in Economics. Besides them, some evaluation studies just examine the publications contained in a limited set of scientific outlets (the so-called Blue Ribbon journals), generally those considered to be the most prestigious among academic economists (see, Conroy and Dusansky, 1995, and Kalaitzidakis et al., 1999). Finally, some supplementary information can be drawn from researchers' webpages or institutional Research Summaries.

In this paper, we have chosen Econlit as our main data source. The main reason underlying this choice is that Econlit provides a much wider coverage of Economics journals (around 680) than SSCI (around 170), together with its accessibility on line. Further, SSCI is a multidisciplinary data base which contains journals in related social sciences- like Geography, Psychology, Sociology, etc.- which can somewhat hinder the search of publications and authors in our field of interest. Indeed, Econlit turns out to be the database most frequently used in this type of studies (see, e.g., the EEA evaluation studies). Admittedly, in constrast to the SSCI, Econlit does not provide impact factors or "half-life" indexes of citations in the different journals (see Bergantiños et al. 2002, for a detailed description of those factors). ${ }^{4}$ One alternative to mend this deficiency would be to consider only those journals in Econlit which are indexed in the SSCI, as Bergantiños et al. (2002) do in their study. However, this strategy would eliminate many journals where Spanish economist have published their research, particularly those in Spanish. In fact, according to those authors, whereas the world share of Economics publications in SSCI journals is 53\%, the Spanish share only reaches $42 \%$ during the second half of the 1990s. Another possibility is to weight the "importance" of each publication in Econlit by adopting alternative bibliometric indicators of quality which, while acknowledging the key

\footnotetext{
4 The highest factor corresponds to a divulgation magazine (The Economist) whose impact almost doubles that of the best placed scholarly journal (Journal of Economic Literature), and is almost three or four times larger than those of the most prestigious journals, like American Economic Review, Econometrica or Journal of Political Economy.
} 
1 Omission of authors who sign in fourth or further place.

2 Omission or errors in affiliation fields. There can also be errors in dates of publication and page numbers.

3 Confusion with the existence of homonyms in departments/institutions or authors's names. Thus, for example, "Banco de España" can appear as "Bank of Spain" or "Banco de Espana".

4 Omission of papers published in an issue of a journal. This problem can be a source of bias against authors who publish in journals with low coverage.

5 Reduced coverage of Spanish journals (only 6 journals up to 2001 and 10 journals since then).

6 Omission of statistical journals where econometricians often publish like, for example, Annals of Statistics, Biometrika, Journal of the Royal Statistical Society (B), Journal of Time Series Analysis, etc. Similar omissions occur for some of the most prestigious journals in Business Economics.

Box 1. Main deficiencies of Econlit

role of citations in weighting scientific output, do not follow that criterion blindly. This is the route we take in this paper.

In sum, the rankings in this study are based on all those publications indexed in Econlit whose authors (nationals or foreigners) are affiliated to a Spanish research unit over the period 1990-1999, as well as those articles authored by Spanish researchers with foreign affiliations. ${ }^{5}$ From this database, we initially elaborated extensive rankings for researchers and institutions which served us to identify the first 120 authors and 50 institutions. Once that information was available, two additional databases were constructed, one for researchers and another for institutions with 1065 and 2215 entries, respectively, that identified articles published in 281 different journals. The coverage of this second database was significantly better than the original one and helped us to construct the final rankings of the Top Twenty institutions and Top Ten researchers reported below. Within the group of universities, we gathered data from both public and private ones.

For each record (article), the following formation is available: Title, Authors, Institution, Journal, Volume and Issue, Number of Pages and Year of Publication. Box 1 summarises the main limitations of the Econlit database emphasising the absence of journals in some scientific fields like Statistics or Applied Mathematics (where some econometricians publish most of their work), and Business Economics (Accounting, Theory of Organization, etc.) that in some Spanish universities are integrated in Economics Departments. In this sense, it is important to highlight from the outset that an important bias is bound to be present against researchers in those areas. We plan to correct these problems in future work using supplementary data sources like Business Elite for Business Economics or the SSCI.

5 The search in Econlit was finished by december, 2001. It is likely that some publications belonging to the period under consideration had not been included at that time. For this reason, we have restricted the rankings to twenty institutions and ten authors in order to minimise the impact of those delays. However, longer rankings based on the available information in that month can be obtained upon request. The list of journals indexed by Econlit and their entry dates in the database can be found at http://www.econlit.org/journal_list.html. 


\subsection{Methodology}

Weighting schemes

To construct publishing-performance indicators we have only considered those articles published in scholarly journals, generally those with a peer-review system. Any other kind of publication, such as working papers, books, chapters in collective volumes, theses, etc., are not considered, given the inherent difficulties in their evaluation. Since the journals have different quality level, it is crucial to use appropriate weighting shemes. A sensible starting point is to admit that no weighting scheme is perfect. ${ }^{6}$ Experience shows us that it is difficult to find two economists that would rank, say, 20 journals in the same way and our initial search in Econolit identified 281 outlets where Spanish economists had published. Therefore, we have constructed our own weighting scheme, labelled $U C 3$, which certainly would be considered as subjective and imperfect by many readers but that, in our opinion, avoids some shortcomings in other available schemes. However, to counter subjectivity, we also use three other weighting schemes available in the literature, labelled as $B A U, K M S A l l$, and $B R$ which are overwied below and whose detailed description can be found in Box 2. It is important to emphasise that the use of different criteria to weight publication performance is highly advisable in this kind of studies due to the partial and complementary nature of each indicator (Martin 1996). Further, the use of different rankings based upon different criteria facilitates obtaining an average ranking that can somewhat integrate the available information contained separately.

Our new $U C 3$ criterion is based on an extension of the cardinal ranking used by the Department of Economics of Universidad Carlos III de Madrid, which is based upon experts' subjective opinions about the "importance" of each journal in terms of impact factors, prestige, acceptance rates, whether is is a general-field or specialised outlet, whether it is a new or long-existing journal, etc. Its main difference with respect to the other weighting schemes considered here is twofold. First, it contains all journals in Econlit where the researchers considered in this article have published, including those journals published in Spanish. Secondly, in comparison with other available cardinal criteria (see below), it exhibits a halfway range of scores, from $\frac{1}{2}$ to 30 , in order to differenciate minor local journals from the very top ones. It was elaborated as an update of the ranking of journals in the 1980s by Laband and Piete (1994), based on impact-adjusted citations per article, taking into account the rapid expansion of publications, new entrants, and the changes in emphasis in the profession about the evolution of traditional journals. It classifies Econlit journals into seven categories. The top category ( 30 points) corresponds to the three major general-interest journals in most weighting schemes (AER, Etca and JPE), plus the Journal of the American Statistical Association (JASA) which can be considered as the top journal in Statistics, indexed by Econlit, where economists publish. Other two high quality general-interest journals plus several top field journals with a long tradition come next in a small layer of journals awarded 20 points,

\footnotetext{
6 A good survey of available schemes can be found in Villar (2002). For an attempt to introduce "axiomatic" considerations in the construction of these schemes, see Palacios-Huerta and Volij (2002).
} 
so that a publication in one of these excellent journals is equivalent to $\frac{2}{3}$ of a publication in the four top journals. The remaining well-known international journals are placed in categories awarded 15 and 8 points, respectively, depending on their scope. This means, for instance, that a publication in (say) the European Economic Review or The Economic Journal is valued as half a publication in the top journals given that, although these outlets are well-known general-interest journals, their submissions often come from European researchers. National journals or less-well known specialised journals, given their limited impact, fall into categories awarded 4, 2 and 1 points. The top Spanish journals are awarded 4 points, so that a publication in them ranks as $\frac{2}{15}$ of a top publication. Finally, the remaining journals in Spanish with a more limited scope, where it is not clear that a refeering process exists, receive $\frac{1}{2}$ point.

The $B A U$ scheme is another cardinal ranking of journals that takes into account both citations and impact factor (see Bauwens 1998, and Bauwens et al. 2002, for a slight modifications). This criterion is used by the Department of Economics of the Universitè Catholiquè de Louvaine to measure the publication performance of economists in Belgium. It classifies 265 Econlit journals into five categories with scores ranging from 1-5. In our opinion, the width of this range is too narrow and few people would agree that a publication in a minor local journal indexed by Econolit only ranks as $\frac{1}{5}$ of a publication in a top journal.

The $K M S A l l$ criterion is a weighting scheme proposed by Kalaitzidakis et al. (2002) that uses the information provided by the Journal of Citation Reports (JCR) on citations received by economic journals to construct a weighting scheme of 147 Econlit journals adjusted by impact, age, self-citations and size of pages. Thus, although it can be considered as a general scheme, it is more restrictive than the two previous criteria. The scoring procedure does not distinguish among a small set of categories, as the other schemes do, and ranges between a maximum value of 1 $(A E R)$ and a minimum value of 0.01 . Thus, the relative value of a minor publication in terms of a top one is $\frac{1}{100}$, a proportion that many people would consider as being too small.

Finally, in contrast with the previous three schemes, the $B R$ scheme is a very restrictive one and corresponds to the extension to 10 top journals by Kalaitzidakis et al. (1999) of the "Blue Ribbon Eight" considered by Conroy and Dusansky (1995). Their weigting scheme ranges from a maximum of $1(A E R)$ to a minimum of 0.034 (EER).

Table 1 presents the correlations among the scores awarded to the 2215 entries in our database according to the different weighting schemes. The lowest correlation is between $B R$ and $B A U$, which is not surprising given that $B A U$ ranks all outlets in Econlit whilst $B R$ only considers 10 journals, whereas the highest correlation is between $K M S A l l$ and $B R$, the two more selective schemes.

In addition to the choice of weighting scheme, there are other important aspects that ought to be considered in this kind of studies. These are: (i) the allocation of a publication to an institution depending either on the affiliation of the author at the time of the publication (as appearing in the publication database) or on the author's current affiliation, (ii) the weighting of the number of authors of each paper $(N)$, (iii) the weighting of the length of the paper, measured in (say) number of AER 
Table 1. Correlations between weighting schemes

\begin{tabular}{lllll}
\hline Weight & UC3 & BAU & KMSAll & BR \\
\hline UC3 & 1.000 & & & \\
BAU & 0.572 & 1.000 & & \\
KMSAll & 0.738 & 0.558 & 1.000 & \\
BR & 0.586 & 0.393 & 0.828 & 1.000 \\
\hline
\end{tabular}

standardized- pages (see, e.g., Baltagi 1998, and Kalaitzidakis et al., 1999, 2002), and (iv) the weighting of institutions when there are multiple affiliations $(A)$ of an author in a given publication.

Regarding the choice of affiliation, both alternatives are interesting. Past production is informative from a historical perspective whereas current affiliation is informative about current human research capital available in each institution. Although the second option can be more useful in signalling the competitive position of an institution at a given moment of time, we choose the first approach in this study, given the extreme difficulties in carrying out an extensive search across research units to identify changes in affiliations during a decade. With regard to the number of authors, we have used two weighting schemes. First, we have used a proportional weight $\frac{1}{N}$ to measure total production by research units so that, if two equivalent papers in the same journal are published by (say) one and two authors of two different research units, each institution would receive an identical score. Secondly, when measuring publishing performance at the individual-researcher level, since the previous proportional weight penalises heavily co-authorship, which is fairly common in Economics, a non-proportional weight given by $1 / \sqrt{N}$ is used as reasonable compromise between the extreme weights of 1 and $\frac{1}{N}$.

As for the length of the paper, it is important to stress that it can only be taken into account for those journals whose adjustment coefficients are available. These are the journals considered by Kalaitzidakis et al. $(1999,2002)$ in their proposed $K M S A l l$ and $B R$ schemes. In order to make comparisons with the rankings in those studies, we only use this criterion for those authors who have published in that set of journals. Hence, for the remaining journals, we only consider the number of authors and the weight for each journal, but not the paper's length. Finally, when an author has signed a paper using several affiliations, we used the weight $1 / A$ to assign the paper proportionally to each of the institutions.

Further considerations: Average-quality publication, timing and size of institutions

Additionally, three further indicators have been considered. The first one is related to the average quality of the publications in each institution and serves to distinguish those research units which get a high position due to their large size from those which, being smaller, get a lower number of publications but of a high quality. To do so, we use the indicator $\overline{U C 3}=\frac{T U C 3}{N A}$ where $T U C 3$ is the total amount of points achieved by a given institution according to the $U C 3$ criterion and $N A$ is the number of articles of that institution. The second one provides a measure of the evolution of research productivity over time by identifying those institutions whose researchers published at the beginning of the 1990s vis-á-vis those who did so at the 


\section{(i) $U C 3$ Scheme}

Description: This is a criterion based on Labband and Piette (1994), and extended to a larger set of journals. The Department of Economics of Universidad Carlos III has elaborated a cardinal score for those journals with the aim of implementing criteria for internal promotion and recruitment.

Included journals: 281 journals in Economics, Econometrics and Financial Economics. Weights: Journals are classified in seven categories, according to the following scoring system: Group A (30 points), Group B+ (20 points), Group B (15 points), Group C (8 points), Group D (4 points), Group E (1 point), Group F ( 0.5 points). Group A journals are AER, Etca, JPE and JASA. For more details, see http://www.eco.uc3m.es/־help/UC3.PDF (ii) $B A U$ Scheme

Description: This criterion is based on a ranking of Belgian institutions and economists for the 1992-1997 period.

Included journals. Articles published in journals where authors are affiliated to at least one Belgian university. Books and chapters are not included.

The journals are those included in Econlit excluding Annals of Public and Cooperative Economics, Cahiers Economiques de Bruxelles, Economisch en Sociaal Tijdschrift, and Tijdschrift voor Economie en Management. Overall, data from 265 journals were gathered. Weights. The weights are obtained as the product of the total number of citations and the impact factor (C x IF) (Citation Reports 1996 data, Social Science Edition). According to this procedure, a score between 1 and 5 is assigned to each journal in the following way: 5 if $\mathrm{C} \times$ IF $>5000 ; 4$ if $450<\mathrm{C} \times$ IF $<5000 ; 3$ if $120<\mathrm{C} \times$ IF $<450 ; 2$ if $25<\mathrm{C} \times$ IF $<120$; and 1 if $\mathrm{C} x \mathrm{IF}<25$ or if there is no data. Journals with 5 points are: AER, Etca, Harvard Business Review, Journal of Economic Literature, Journal of Finance, Journal of Financial Economics, JPE and Quarterly Journal of Economics. For more details, see http://www.core.ucl.ac.be/econometrics/Bauwens/Rankings/rankings.htm.

(iii) $K M S$ All Scheme

Description: This criterion is based on Kalaitzidakis et al. (2002) who rank European institutions according to publications in a subset of 147 Econlit journals. Their weighting scheme is based on information obtained from the Journal of Citation Reports (JCR) about the citations received in 1998 of articles published in the 1994-1998 period excluding selfcitations and adjusted for impact and size.

Included journals. Articles published in 147 Econlit journals.

Weigths: It uses a continuous scoring system, based on an update of Laband and Piette's (1994) approach, ranging from 1 to 0.01. The five top journals are AER (1), Etca (0.97), JPE (0.65), JET (0.59) and QJE (0.58). from includes an adjustment factor for the size of the pages. This is the reason why the number of pages and not the number of articles is considered. For further information, see www.econ.ucy.ac.cy/papers/0110.pdf

(iv) $B R$ Scheme

Description: This criterion is based on Kalaitzidakis et al. (1999) who use Laband and Piette's (1994) weighting approach updated to the period under consideration (1991-1996) Included journals: Ten journals considered by the authors to be the most prestigious in Economics (AER, ECTCA, EER, EJ, JET, JME, JPE, QJE, REStud, REStat). It includes an adjustment factor for the standard size of pages in each journal.

Weights: The weights are AER=1.0, ECTCA=0.890, EJ $=0.128, \mathrm{JET}=0.511, \mathrm{JME}=0.593$, $\mathrm{JPE}=0.791, \mathrm{QJE}=0.645, \mathrm{REStud}=0.476, \mathrm{REStat}=0.145, \mathrm{EER}=0.036$. For further information, see www.econ.ucy.ac.cy/papers/0110.pdf

Box 2. Description of criteria used to elaborate rankings 
end of the decade. For that, we use a weighted $U C 3$, denoted as $U C 3(t)$, where the discount factor $t(i)=1-(0.05 \cdot i)$, with $i=1999-$ year of publication. This indicator serves to distinguish between institutions where research is expanding from those where it is lagging over time.

Finally, the third indicator somewhat corrects for the size of the institutions in order to provide a ranking of production per member. Ideally, one would like to normalise the total number of publications at a given institution in each year of the sample by its members. However, this correction turns out to be impossible due to the inherent difficulties in identifying the correct size of each research unit over a decade, and to the existence of different departments in universities where research in Economics is undertaken. For instance, there are universities where the areas of Economics, Applied Economics, Business or Econometrics belong to the same department whereas in others they correspond to different departments. Moreover, there are research units which were only created in the late 1980s and whose size has widely varied along the 1990s, particularly in the case of new universities. There is, however, an indirect strategy is to correct for size (see, e.g., Bauwens et al. 2002) which consists of computing the ratio of the (quality weighted) total number of publications at a given institution, over the 1990s, and the number of authors who have contributed to those publications, rather than total membership. The problem with this scaling procedure is that it would favour institutions whose publications are highly concentrated among a few authors. For example, consider two research units with 10 and 100 researchers, respectively, where each researcher in the first institution has published a 1-point article whilst only one researcher has published a 1-point article in the second institution and the remaining faculty have published nothing. The proposed scaling procedure would rank both research units equally in per capita terms, disregarding any consideration about its distribution. To correct somehow for this problem, we have used the above-mentioned indicator of production per author, denoted as $U C 3 A$, eliminating those universities and research centers which have less than 20 and 10 authors, respectively, over the decade, on the grounds that membership at the former is larger than at the latter.

\section{Results}

Next, the rankings of institutions and researchers elaborated with the above-mentioned bibliometric indicators are presented.

\subsection{Rankings of institutions}

Concerning institutions, Table 2 shows the ranking of the Top Twenty research units obtained from the general schemes $U C 3$ and $B A U$, as well as the number of articles $(N A)$ for each institution. Table 3 , in turn, displays the ranking obtained from the more selective $K M S A l l$ and $B R$ criteria. As mentioned above, we report results obtained with the proportional weight $1 / N$ for the number of co-authors in a given publication. The scores have been normalised to 100 for the top-ranked institution. As can be observed, UCIII, UPF, UAB, Alicante and UPV, as well as the 
Table 2. Ranking of institutions: UC3 and BAU schemes

\begin{tabular}{rlrrrlrr}
\hline Rank & Institution & NA & UC3 & Rank & Institution & NA & BAU \\
\hline 1 & UCIII & 259 & 100.00 & 1 & UCIII & 231 & 100.00 \\
2 & UPF & 247 & 82.23 & 2 & UPF & 216 & 82.73 \\
3 & U. Alicante & 172 & 57.11 & 3 & UAB & 155 & 56.99 \\
4 & UAB & 180 & 52.84 & 4 & U. Alicante & 148 & 54.06 \\
5 & IAE & 104 & 50.22 & 5 & UPV & 163 & 52.74 \\
6 & UPV & 179 & 46.63 & 6 & U. Valencia & 230 & 52.42 \\
7 & U. Valencia & 310 & 35.13 & 7 & B. de España & 215 & 50.20 \\
8 & B. de España & 224 & 30.74 & 8 & U. Complutense & 196 & 50.08 \\
9 & CEMFI & 75 & 29.84 & 9 & IAE & 100 & 46.48 \\
10 & U. Complutense & 242 & 28.72 & 10 & U. Zaragoza & 142 & 35.09 \\
11 & U. Zaragoza & 186 & 25.11 & 11 & CEMFI & 69 & 28.48 \\
12 & U.P. Navarra & 80 & 13.84 & 12 & U. Barcelona & 83 & 24.70 \\
13 & U. Barcelona & 122 & 12.03 & 13 & U. Alcalá & 60 & 16.38 \\
14 & U. Santiago & 25 & 9.39 & 14 & U. P. Navarra & 62 & 14.56 \\
15 & IVIE & 50 & 9.31 & 15 & U. Oviedo & 66 & 13.11 \\
16 & U. Vigo & 41 & 9.13 & 16 & FEDEA & 58 & 11.55 \\
17 & U. Alcalá & 71 & 8.91 & 17 & U. Autónoma Madrid & 35 & 9.95 \\
18 & FEDEA & 65 & 7.90 & 18 & IVIE & 44 & 9.66 \\
19 & U. Oviedo & 81 & 7.59 & 19 & U. Vigo & 33 & 9.25 \\
20 & U. Cantabria & 36 & 7.45 & 20 & U. Salamanca & 31 & 9.23 \\
\hline
\end{tabular}

Source: Econlit (OVID Technologies) and own elaboration. Weight: 1/N

Instituto de Análisis Económico (IAE/CSIC), are placed in the top positions. If we were to consider UAB and IAE as a single research unit (labelled as "Campus de Bellaterra" by Bergantiños et al. 2002) due to the strong links among the researchers in both institutions, then this group becomes the top one in terms of the $U C 3$ and $B A U$ criteria, while UPF carries the leadership when the more selective $K M S A l l$ and $B R$ schemes are considered. Regarding research centers, the top ones, besides IAE, are CEMFI, FEDEA and IVIE. The absence of private universities in these rankings is noteworthy. This, in some cases, may be due to their recent creation and, in many others, to the fact that these institutions give much more importance to teaching than to research duties. Broadly speaking, one could define these centers as colleges, rather than genuine research units.

Lastly, Table 4 displays the ranking of the Top Ten institutions in terms of the $\overline{U C 3}, U C 3(t)$ and $U C 3 A$ indicators. ${ }^{7}$ As reported in the left column, IAE and CEMFI are the two research units whith higher average quality of their publications according to $U C 3$ scheme. In terms of the scoring system of the $U C 3$ scheme, their average quality publication falls into the category awarded 8 points. Likewise, the center column points out that UCIII and UPF are the two institutions where the bulk of their publications has appeared toward the end of the 1990s rather than at the beginning. Finally, the right column clearly identifies IAE as the research unit with the largest number of publications per author.

7 We restrict to 10 the number of institutions in this case because the scores for the remaining institutions were so similar that is difficult, in the presence of measurement errors, to discriminate among them. 
Table 3. Ranking of institutions : KMSAll and BR schemes

\begin{tabular}{rlrr|llrr}
\hline Rank & Institution & NA & \multicolumn{1}{r}{ KMSAll } & Rank & Institution & NA & BR \\
\hline 1 & UPF & 109 & 100.00 & 1 & UPF & 55 & 100.00 \\
2 & UC III & 108 & 95.36 & 2 & UCIII & 27 & 56.26 \\
3 & IAE & 55 & 46.75 & 3 & UAB & 17 & 43.55 \\
4 & UAB & 67 & 46.11 & 4 & IAE & 17 & 38.94 \\
5 & U. Alicante & 74 & 36.47 & 5 & U. Alicante & 8 & 24.82 \\
6 & CEMFI & 29 & 24.89 & 6 & CEMFI & 10 & 15.46 \\
7 & B. de España & 26 & 14.85 & 7 & B. de España & 8 & 6.16 \\
8 & UPV & 54 & 13.06 & 8 & FEDEA & 5 & 4.01 \\
9 & U. Zaragoza & 27 & 7.49 & 9 & UPV & 1 & 3.93 \\
10 & U. Cantabria & 3 & 5.26 & 10 & U. Salamanca & 1 & 3.47 \\
11 & U. Valencia & 29 & 5.25 & 11 & U. Zaragoza & 9 & 2.38 \\
12 & U. Complutense & 34 & 5.18 & 12 & U. Complutense & 2 & 2.25 \\
13 & FEDEA & 19 & 5.03 & 13 & U. Vigo & 2 & 1.88 \\
14 & U. Santiago & 9 & 4.85 & 14 & U. Valencia & 3 & 1.55 \\
15 & IVIE & 18 & 4.73 & 15 & U. P.Navarra & 2 & 1.25 \\
16 & U. Salamanca & 4 & 4.66 & 16 & U Alcalá & 3 & 109 \\
17 & U. P. Navarra & 21 & 2.89 & 17 & M Economía & 3 & 0.21 \\
18 & U. Vigo & 10 & 2.68 & 18 & IVIE & 1 & 0.13 \\
19 & M ${ }^{o}$.Economía & 6 & 2.19 & 19 & U. Oviedo & 1 & 0.03 \\
20 & U. Alcalá & 6 & 1.96 & 20 & & & \\
\hline
\end{tabular}

Source: Econlit (OVID Technologies) and own elaboration.Weight: 1/N

Table 4. Ranking of institutions: $\overline{U C 3}$, UC3 (t) and UC3A schemes

\begin{tabular}{rlrrlrrlr}
\hline Rank & Institution & $\overline{\text { UC3 }}$ & Rank & Institution & UC3 (t) & Rank & Institution & UC3A \\
\hline 1 & IAE & 100.00 & 1 & UCIII & 100.00 & 1 & IAE & 100.00 \\
2 & CEMFI & 83.06 & 2 & UPF & 82.39 & 2 & Alicante & 31.74 \\
3 & UCIII & 79.94 & 3 & UPV & 71.43 & 3 & CEMFI & 29.71 \\
4 & U. Santiago & 77.71 & 4 & UAB & 70.32 & 4 & UCIII & 29.50 \\
5 & UPF & 68.94 & 5 & IAE & 67.96 & 5 & UPF & 27.68 \\
6 & U. Alicante & 68.79 & 6 & U. Alicante & 61.78 & 6 & UPV & 24.76 \\
7 & UAB & 60.77 & 7 & B. de España & 52.46 & 7 & UAB & 22.26 \\
8 & UPV & 53.93 & 8 & U. Valencia & 49.29 & 8 & FEDEA & 17.41 \\
9 & U. Vigo & 46.06 & 9 & U. Complutense & 43.74 & 9 & IVIE & 16.26 \\
10 & U. Cantabria & 42.79 & 10 & CEMFI & 39.65 & 10 & B. de España & 12.50 \\
\hline
\end{tabular}

Source: Econlit (OVID Technologies) and own elaboration.

\subsection{Rankings of researchers}

Regarding the ranking of researchers, Table 5 shows the classifications obtained for the Top Ten most productive researchers according to the $U C 3$ and $B A U$ criteria while Table 6 does it according to the more restrictive $K M S A l l$ and $B R$ schemes. In all cases, a weight of $1 / \sqrt{N}$ for co-authorship has been used. Jordi Galí (UPF and NYU), followed by Fabio Canova (UPF), J. Victor Ríos-Rull (Penn), Manuel Santos (Arizona State) and Xavier Vives (IAE) are in the top three positions, depending on which indicator is being used in each instance. It should be pointed out that, with a few exceptions, a large number of those in the top positions have developed 
Table 5. Ranking of researchers: UC3 and BAU schemes

\begin{tabular}{rlrrlr}
\hline Rank & Author & UC3 & Rank & Author & BAU \\
\hline 1 & Gali, J & 100 & 1 & Canova, F & 100 \\
2 & Vives, X & 77.12 & 2 & Gali, J & 96.76 \\
3 & Canova, F & 74.94 & 3 & Vives, X & 80.04 \\
4 & Santos, M & 63.50 & 4 & Sala-i-Martín, X & 75.17 \\
5 & Sala-i-Martín, X & 60.25 & 5 & Dolado, JJ & 60.39 \\
6 & Vega- Redondo, F & 56.95 & 6 & Santos, M & 58.28 \\
7 & Dolado, JJ & 55.91 & 7 & Sentana, E & 50.91 \\
8 & Serrano, R & 52.18 & 8 & Silvestre, J & 49.28 \\
9 & Sentana, E & 48.09 & 9 & Serrano, R & 48.19 \\
10 & Rios- Rull, JV & 39.53 & 10 & Vega- Redondo, F & 45.32 \\
\hline
\end{tabular}

weight: $1 / \sqrt{\mathrm{N}}$

Table 6. Ranking of researchers: KMSAll and BR schemes

\begin{tabular}{rlrrlr}
\hline Rank & Author & KMSAll & Rank & Author & BR \\
\hline 1 & Gali, J & 100.00 & 1 & Gali, J & 100 \\
2 & Santos, M & 81.67 & 2 & Santos, M & 75.51 \\
3 & Canova, F & 69.77 & 3 & Rios- Rull, JV & 60.47 \\
4 & Sala-i- Martín, X & 63.20 & 4 & Sala-i-Martín, X & 60.03 \\
5 & Rios-Rull, V & 51.98 & 5 & Serrano, R & 37.79 \\
6 & Serrano, R & 50.89 & 6 & Boldrin, M & 36.63 \\
7 & Vives, X & 49.11 & 7 & Esteban, JM & 34.45 \\
8 & Vega-Redondo, F & 47.74 & 8 & Marimón, R & 29.65 \\
9 & Sentana, E & 42.82 & 9 & Barberá, S & 29.36 \\
10 & Arellano, M & 40.53 & 10 & Vives, X & 26.16 \\
\hline
\end{tabular}

weight: $1 / \sqrt{\mathrm{N}}$

their research careers in foreign universities. It is also noteworthy that some of the best- known Spanish academic economists occupy slightly lower positions below the Top Ten. This could be due to the concentration of a large share of their research before the 1990s, or to having their publications in journals of the areas of Statistics or Corporate/Business Economics, that are not registered in Econlit. Another interesting fact to highlight is that, even though researchers at UPF occupy three of the five first positions of the ranking of researchers, this university is only second in the ranking of institutions according to the $U C 3$ and $B A U$ criteria. This may be caused by having a high concentration of publications among a very selective group of researchers. By contrast, the fact that UCIII comes the first in these volume-oriented rankings, despite having less researchers in the Top Ten, can be due to the higher dispersion of their scientific production among its researchers.

\subsection{Distribution of publications by journals}

Besides the rankings of institutions and researchers, we have also analysed the distribution of publications by journal with the aim of identifying those outlets which contain more publications by Spanish authors. In order to save space, rather than reporting detailed evidence for the 281 Econlit journals identified in our sample we summarise in the sequel the main conclusions reached from the analysis of the 
distribution of publications (1065) by journals for the first 120 authors. ${ }^{8}$ Investigaciones Económicas, Economics Letters and Journal of Economic Theory are the journals with the largest number of published articles. Moreover, the number of articles published in the second half of the 1990s (661) has increased by $64 \%$ with respect to those appearing in the first half of the decade. When considering the distribution of publications restricted to the Blue Ribbon journals, the growth rate in the number of publications is $22 \%$. Overall, 193 articles were published in those journals, being $J E T$ (52) and $E E R$ (39) the outlets with more articles while $J P E$ (5) and $Q J E(3)$ are the ones containing less publications.

Further, we have also studied the evolution over time of the number of coauthored articles, which is an indicator of the degree of collaboration among researchers. It was found that there has been a progressive increase, from 1.56 to 1.89 , in the average of the number of authors by article and an upward trend, with the exception of 1999 , in the total number of joint publications during the decade.

\section{Citation-based rankings}

In this section we measure the impact of the publications in terms of the number of citations subsequently generated in the research of other authors. In Economics, as in other scientific disciplines, it is a well-known fact that there is a core of prestigious authors that do not publish frequently but whose research cause a great impact. Those authors will not be necessarily placed in top positions of the previous rankings in spite of the existence of a general consensus about the importance of their publications. In order to measure their influence we use the number of citations weighted by author for those articles published and cited during the 1990s. The number of citations corresponds to the times that a publication appears in the list of references of an article. For example, according to the impact indicator, if an article with three authors has had 60 citations during the 1990s, the indicator will assign 20 citations for each author. The search of the number of citations has been undertaken with the help of the on-line access to the Web of Science from the Institute of Scientific Information. Table 7 shows the ranking of the 10 most cited researchers obtained through this indicator. The outstanding position obtained by Xavier Sala-i-Martín, whose papers on Growth Theory have had a strong impact on the literature, may be highlighted. Alternatively, another indicator of citations during the 1990s has been calculated. This indicator, presented in Table 8, shows the impact during the 1990s of articles published at any moment of time. In this case, the first position is occupied by Andreu Mas-Colell, whose citations almost double those of the following researchers. Finally, Table 9 displays a list of the 10 articles written during the 1990s that have received more quotations during that decade. In this classification, as it happened with Table 11, the article entitled "Convergence" (JPE 1992) by Xavier Sala-i-Martín, co-authored with Robert Barro, has a number of citations that almost doubles those of the second most cited article.

\footnotetext{
${ }^{8}$ Detailed evidence can be found in the working paper version of this study (see Dolado et al. 2000)
} 
Table 7. Ten most cited authors (papers published and cited in the 1990s)

\begin{tabular}{rlr}
\hline Rank & Author & Citations $^{\mathrm{a}}$ \\
\hline 1 & Sala-i-Martín, X & 397.5 \\
2 & Galí, J & 191.3 \\
3 & Vives, X & 123.0 \\
4 & Saint-Paul, G & 121.5 \\
5 & Arellano, M & 105.5 \\
6 & Canova, F & 83.8 \\
7 & Boldrin, M & 79.2 \\
8 & Motta, M & 71.5 \\
9 & Marcet, A & 67.5 \\
10 & Dolado, J & 65.6 \\
\hline
\end{tabular}

Source: Web of Science (ISI)

${ }^{\text {a }}$ Citations weighted by number of authors

Table 8. Ten most cited authors (papers published any time and cited in the 1990s)

\begin{tabular}{rlr}
\hline Pos & Author & Citations \\
\hline 1 & Mas Colell, A & 1087 \\
2 & Sala-i-Martín, X & 653 \\
3 & Dolado, J & 505 \\
4 & Vives, X & 455 \\
5 & Arellano, M & 325 \\
6 & Marcet, A & 285 \\
7 & Canova, F & 283 \\
8 & Gali, J & 258 \\
9 & Barberá, S & 219 \\
10 & Bentolila, S & 180 \\
\hline
\end{tabular}

Source: Web of Science (ISI)

\section{Conclusions}

In this paper we have elaborated rankings about research in Economics of institutions and researchers during the 1990s by using several bibliometric indicators that try to measure the quality of those scholarly journals where economists publish. The main conclusions stemming from those rankings (bearing in mind the existing biases in the database that we used) may be summarized as follows:

- Concerning research units, we found that, irrespectively of the criterion used, Alicante, IAE, CEMFI , UAB and, UPF, are the top institutions with larger and better scientific production. When considering total number of publications included in Econlit, the "Campus de Bellaterra" (UAB and IAE) is in the first position, whereas, when only a restricted number of top journals is used, UPF comes clearly first. In terms of publications per author, IAE turns out to be the most productive research unit. 
Table 9. Ten most cited papers published in the 1990s

\begin{tabular}{|c|c|c|c|}
\hline Pos & Author & Article & Citations \\
\hline 1 & Sala-i- Martín, X. & "Convergence" JPE 1992 (with R. Barro) & 293 \\
\hline 2 & Arellano, M. & $\begin{array}{l}\text { "Some tests of specification for panel data: } \\
\text { Monte-Carlo evidence and an application to } \\
\text { employment equations", Rev Econ Stud, } 1991 \\
\text { (with S.Bond) }\end{array}$ & 156 \\
\hline 3 & Dolado, JJ. & $\begin{array}{l}\text { "The power of cointegration tests", Oxford B } \\
\text { Econ Stats, } 1992 \text { (with J.Kremers and } \\
\text { N. Ericsson) }\end{array}$ & 130 \\
\hline 4 & Bentolila, S. & $\begin{array}{l}\text { "Firing costs and labor demand : How bad is } \\
\text { eurosclerosis?" Rev Econ Stud, } 1990 \\
\text { (with G.Bertola) }\end{array}$ & 92 \\
\hline 5 & Galí, J. & $\begin{array}{l}\text { "How well does the IS/LM model fit post war US } \\
\text { data?" QJE, } 1992\end{array}$ & 63 \\
\hline 6 & Sala-i-Martín, X. & $\begin{array}{l}\text { "Public Finance in models of endogenous growth" } \\
\text { Rev Econ Stud, } 1992 \text { (with R. Barro) }\end{array}$ & 60 \\
\hline 6 & Boldrin, M. & $\begin{array}{l}\text { "Equilibrium models displaying endogenous } \\
\text { fluctuations and chaos: A survey" JME, } 1990 \\
\text { (with M. Woodford) }\end{array}$ & 60 \\
\hline 8 & García-Milá, T. & $\begin{array}{l}\text { "The contribution of publicly provided inputs to } \\
\text { states economies" Reg Sci Urban Econ, } 1992 \\
\text { (with T. McGuire) }\end{array}$ & 49 \\
\hline 9 & Vives, $\mathrm{X}$. & $\begin{array}{l}\text { "Nash equilibrium with strategic complementari- } \\
\text { ties", J Math Econ, } 1990\end{array}$ & 48 \\
\hline 10 & Sala-i-Martín, X. & $\begin{array}{l}\text { "Capital Mobility in Neoclassical Models of } \\
\text { Growth" AER, } 1995 \text { (with R. Barro and } \\
\text { N.G. Mankiw) }\end{array}$ & 48 \\
\hline
\end{tabular}

Source: Web of Science (ISI)

- Concerning researchers, Jordi Galí (UPF) was the most outstanding researcher during the last decade, closely followed by Fabio Canova (UPF), J. Victor RiosRull (Penn), Manuel Santos (Arizona State) and Xavier Vives (IAE), depending on the criterion being used.

- Concerning the impact of the publications, measured by the number of citations weighted by the number of authors, we found that Xavier Sala-i-Martín is the most influential reasearcher, and that his article "Convergence" (JPE 1992, with R. Barro) was the most cited paper during the last decade. If the index of citations is extended to include references to articles published during or before the 1990s, the most influential author by far turns out to be Andreu Mas-Colell

Regarding issues that may be dealt with in future research, we highlight the following: (i) analysing the link between public financing and the quality of scientific production of those research units that receive funding; (ii) elaborating rankings of institutions that consider their size in terms of membership; (iii) examining the dependence of the scientific productivity of each institution on its most prolific researchers, and (iv) updating the sample period beyond 1999. 


\section{References}

Baltagi, B. (1998) Worldwide Institutional Rankings in Econometrics: 1989-1995. Econometric Theory 14: $1-43$

Bauwens, L. (1998) A New Method to Rank University Research in Economics in Belgium. CORE, Mimeo

Bauwens, L., Kirman, A., Lubrano, M., Protopopescu, C. (2002) Ranking European Economic Departments: a Statistical Approach. Mimeo

Bergantiños, G. , Da Rocha, J. M., Polome, P. (2002) La Investigación Española en Economía:19951999. Investigaciones Económicas 26: 373-392

Conroy, E., Dusansky, R. (1995) The Productivity of Economics departmemts on the US: Publications in the Core Journals. Journal of Economic Literature 33: 1966-1971

Coupé, T. (2000) Revealed Preferences: Worldwide Ranking of Economists and Economics Departments. ECARES (ULB), Mimeo

Dolado, J.J., García-Romero, A., Zamarro, G. (2000) Rankings de Investigación en Economía en España: Instituciones y Autores (1990-1999). D.T. FEDEA: 2001-2010 (available at www.fedea.es)

Dusansky, R., Vernon, C. (1998) Rankings of US Economics Departments. Journal of Economic Perspectives 12 : $157-170$

Fusfeld, D. (1956) The Program of the American Economic Association Meetings. American Economic Review 46: 642-644

García, P., Montañés, A., Sanz, F. (1999a) La Investigación en Economía en España: Mercado Nacional versus Mercado Internacional. Universidad de Zaragoza, Mimeo

García, P., Lafuente, A., Montañés, A., Sanz, F. (1999b) Producción Científica en Economía según Publicaciones en Revistas Internacionales. Papeles de Economía Española 81: 49-57

Graves, P.E., Marchand, J. R., Thompson, R. (1982) Economics Departmental Rankings: Research Incentives, Constraints and Efficiency. American Economic Review 72: 1131-1141

Kalaitzidakis, P., Mamuneas, M., Stengos, T. (1999) European Economics: An Analysis Based on Publications in the Core Journals. European Economic Review 43: 1150-1168

Kalaitzidakis, P., Mamuneas, M., Stengos, T. (2002) Rankings of Academic Journals and Institutions in Economics. University of Cyprus, Mimeo

Kirman, A., Dahl, M. (1994) Economic Research in Europe. European Economic Review 38: 505-522

Laband D., Piette, M. (1994) The Relative Impacts of Economic Journals: 1970-1990. Jounal of Economic Literature 32: 640-666

Martin, B. (1996) The Use of Multiple Indicators in the Assessment of Basic Research. Scientometrics 36: $343-362$

Medoff, M. A. (1996) A Citation-based Analysis of Economists and Economics programs. American Economist 40: 40-46

OCYT (1999) Indicadores del Sistema Español de Ciencia y Tecnología. Presidencia del Gobierno, Madrid

Palacios-Huerta, I., Volij, O. (2002) The Measurement of Intellectual Influence. Brown University, Mimeo

Sanz, E., García-Zorita, C., Modrego, A., García-Romero, A. (1999) La Investigación Española en Economía a través de las Publicaciones Nacionales e Internacionales en el Período 1990-1995. Revista de Economía Aplicada 20: 113-137

Scott, L. C., Mitias, P. M. (1996) Trends in Rankings of Economics Departments in the US: An Update. Economic Inquiry 34: 378-400

Thursby, J. (2000) What Do We Say About Ourselves and What Does It Mean: Yet Another Look at Economics Deparment Research. Journal of Economic Literature 38: 383-404

Urrutia, J. (1993) La Investigación Española En Economía. Política Científica. Papeles de Economía Española 3: 41-47

Villar, A. (2002) La Evaluación de la Investigación en Economía. Universidad de Alicante, Mimeo 